Article

\title{
Parental Attitudes toward Artificial Intelligence-Driven Precision Medicine Technologies in Pediatric Healthcare
}

\author{
Bryan A. Sisk ${ }^{1, *(\mathbb{D}}$, Alison L. Antes ${ }^{2}$, Sara Burrous ${ }^{3}$ and James M. DuBois ${ }^{2}$ \\ 1 Department of Pediatrics, Division of Hematology/Oncology, Washington University School of Medicine, \\ St. Louis, MO 63110, USA \\ 2 Department of Medicine, Washington University School of Medicine, St. Louis, MO 63110, USA; \\ aantes@wustl.edu (A.L.A.); duboisjm@wustl.edu (J.M.D.) \\ 3 Brown School, Washington University, St. Louis, MO 63130, USA; sburrous@wustl.edu \\ * Correspondence: siskb@wustl.edu; Tel.: +314-273-9084
}

Received: 14 August 2020; Accepted: 17 September 2020; Published: 20 September 2020

\begin{abstract}
Precision medicine relies upon artificial intelligence (AI)-driven technologies that raise ethical and practical concerns. In this study, we developed and validated a measure of parental openness and concerns with AI-driven technologies in their child's healthcare. In this cross-sectional survey, we enrolled parents of children $<18$ years in 2 rounds for exploratory $(n=418)$ and confirmatory $(n=386)$ factor analysis. We developed a 12-item measure of parental openness to AI-driven technologies, and a 33-item measure identifying concerns that parents found important when considering these technologies. We also evaluated associations between openness and attitudes, beliefs, personality traits, and demographics. Parents $(N=804)$ reported mean openness to AI-driven technologies of $\mathrm{M}=3.4 / 5, \mathrm{SD}=0.9$. We identified seven concerns that parents considered important when evaluating these technologies: quality/accuracy, privacy, shared decision making, convenience, cost, human element of care, and social justice. In multivariable linear regression, parental openness was positively associated with quality (beta $=0.23$ ), convenience (beta $=0.16)$, and cost (beta $=0.11$ ), as well as faith in technology (beta $=0.23$ ) and trust in health information systems (beta $=0.12$ ). Parental openness was negatively associated with the perceived importance of shared decision making (beta $=-0.16$ ) and being female (beta $=-0.12$ ). Developers might support parental openness by addressing these concerns during the development and implementation of novel AI-driven technologies.
\end{abstract}

Keywords: pediatrics; personalized medicine; ethics; biomedical technology; child health; artificial intelligence; machine learning; precision medicine

\section{Introduction}

Precision medicine offers the hope of transforming healthcare by developing more accurate and effective strategies to diagnose, prevent, and treat diseases by considering an individual's genetic, environmental, and lifestyle characteristics [1,2]. To fulfill these hopes, precision medicine interventions require access to vast amounts of personal-level data and patient information, as well as artificial intelligence (AI) algorithms capable of analyzing these large datasets [3]. Recent advances in AI technologies, such as machine learning and deep learning, have further increased enthusiasm about the prospects of precision medicine transforming healthcare [4-9]. In pediatrics, AI-driven technologies are beginning to enter clinical studies in the management of diabetes mellitus [10], asthma [11], and cancer [12]. 
However, these evolving AI-driven technologies also raise ethical and practical concerns [3], especially in pediatrics. For example, large genetic, environmental, and lifestyle datasets from diverse populations of children are necessary for precision medicine to advance. Some parents might worry about the privacy of their child's data or the transparency of how these data will be used. Other parents might worry about the impact of these interventions on the clinician-family relationship. Some have argued, for example, that an influx of AI-driven technologies will further increase the clinician's reliance on computers and electronic medical records at the expense of genuine human engagement [13].

For the field of pediatrics to realize the benefits of precision medicine, researchers and developers must have access to large amounts of diverse data and children must utilize these technologies. Parental openness and support of these technologies will likely expedite this development. As such, it is imperative to understand the ethical and practical concerns that affect parental openness to these AI-driven technologies. In this study, we developed and validated a novel measure of parental openness to the use of AI-driven healthcare technologies in their child's medical care, and we identified factors that parents considered important in evaluating these technologies.

\section{Materials and Methods}

We report this study in keeping with the Checklist for Reporting Results of Internet E-Surveys (CHERRIES) [14]. (Appendix A) This project proceeded in several stages: expert interviews; literature review; item writing; cognitive interviewing and item revision; and two rounds of survey distribution for exploratory and confirmatory factor analysis.

\subsection{Item Writing}

To establish the content to be presented in the original measure, we conducted seven professional informant interviews with bioinformaticians, bioethicists, health lawyers, and physicians. We asked experts to provide their definition of AI, how they would explain AI to non-experts, to highlight clinical examples of AI (both present and future), and to enumerate potential concerns and benefits of $\mathrm{AI}$ in healthcare. We interviewed these leading experts to identify key ethical and practical concerns and to ensure our interpretation of the literature was accurate. We cross-referenced their responses with a literature review of more than 300 articles. For this literature review, we consulted with a medical librarian and used Boolean logic to search PubMed, Scopus, and Embase for articles related to "artificial intelligence", "machine learning", "big data", and "health care." We subsequently searched for clinical applications, ethical concerns, and patient perspectives within these broad searches. We did not restrict searches to pediatrics in order to understand the broad landscape of the AI field of study. After screening, we identified more than 300 articles related to practical and ethical aspects of AI. Additionally, we identified review articles and commentaries that highlighted major ethical issues in the use of AI in healthcare [3,15-19]. From this review, we developed a framework of nine factors that might influence openness to AI-driven healthcare interventions in pediatrics: privacy, transparency, human element of care, social justice, societal cost, personal cost, quality/accuracy, access to care, and access to knowledge. We hypothesized that these factors represented latent constructs that captured the breadth of parental concerns, and we wrote items that targeted each of these constructs.

We next developed an original measure, Attitudes toward Artificial Intelligence in Pediatric Healthcare (AAIH-P), to assess openness to the use of AI-driven technologies in their child's healthcare and to identify concerns that parents considered important when considering engagement with these devices. This new measure consisted of a general openness scale and a scale that measured the importance of various concerns in the parent's consideration of these technologies. We developed the openness scale with the intention of understanding parental openness to a variety of AI-driven applications. We created the concerns scale with the goal of determining whether our hypothesized factors represented underlying latent constructs, and whether these concerns were associated with the openness scale. 
Of note, we opted to avoid using the terms 'artificial intelligence' or 'machine learning' in these measures because of misconceptions and complexity associated with these terms, based on feedback from informant interviews with professionals. We also asked these professionals how they would describe AI or machine learning to lay audiences. These descriptions focused on the need for large amounts of data, the ability to make comparisons to many other people similar to the patient, and the unique clinical functions these AI-driven technologies might offer. Due to this, we opted to describe characteristics of the technologies without labeling them as 'artificial intelligence' or 'machine learning'. During cognitive interviews, parents preferred the terms 'computer programs' and 'devices', so we opted for this phrasing.

The general openness scale asked participants, "How open are you to allowing computer programs to do the following things?" Participants were asked to read 12 items and select their level of openness on a five-point Likert scale ranging from 'not at all open' (1) to 'extremely open' (5). These 12 items represented four different AI-driven healthcare functions, including diagnosis (e.g., "Determine if your child broke a bone"), risk prediction (e.g., "Predict your child's risk of developing depression in the future"), treatment selection (e.g., "Decide on the best treatment for your child's diabetes"), and medical guidance (e.g., "Give you advice on how to prevent your child's asthma attacks") (Appendix B). We included interventions that we believed represented a wide range of emotional intensity for the respondents. This determination of emotional intensity was based on clinical expertise of one author (BAS) in treating children with minor complaints (e.g., ear infections) and diagnosing children with serious, life-threatening diagnoses (e.g., cancer). To support face and content validity, we asked parents during cognitive interviews about their emotional reactions to the range of diagnoses, and whether they were familiar with these diagnoses.

The second component of this measure aimed to identify concerns that parents found important when considering the use of AI-driven healthcare interventions in their child's medical care. Participants were asked, "When you think of using these new devices, how important are the following details to you?" Each of the items described a potential aspect of AI-driven healthcare interventions that might affect openness. For example, "Whether these devices are better than your child's doctor at figuring out why your child is sick." Participants selected how important these items were on a five-point Likert scale, ranging from 'not important' (1) to 'extremely important' (5). We drafted 57 initial survey items that targeted 8 hypothetical constructs (collapsing personal cost and societal cost into a single construct). We wrote 4 to 10 items per hypothetical factor, using both positive and negative valence to increase variance in responses.

After drafting this measure, we performed 11 cognitive interviews to ensure face validity, item clarity, and content validity. We subsequently revised the measure before distributing [20]. For these cognitive interviews, we recruited mothers and fathers whose children were younger than 18 years old with a broad range of racial/ethnic, professional, socioeconomic, and educational backgrounds. To identify participants for these cognitive interviews, members of the research team approached acquaintances who could provide diverse perspectives. We prioritized diversity in education level and racial background. In these interviews, we reviewed surveys item-by-item for readability and clarity. For select items, we asked interviewees to rephrase the question in their own words, to ensure understandability. We also asked participants if they recommended any changes to information, scenarios, wording, or content. For any problematic questions or terminology, we asked what made the question hard to answer and what might help them to answer the question. We also learned about parents' emotional reactions to the range of diagnoses, and whether they were familiar with these diagnoses. Lastly, we asked for general comments about the measure and scope of the items. Most commonly, parents raised concerns with specific words of phrasings that were confusing. Parents did not raise concerns about content of scenarios. We also assessed for reading ease and grade level, achieving Flesch-Kincaid Grade Level of 7.6. 


\subsection{Survey Participants}

We employed criterion-based sampling to recruit participants using Amazon's Mechanical Turk (MTurk), a web-based service that matches 'requesters' with 'workers' to complete various 'human intelligence tasks' (HITs). Participants were required to be parents whose children were all 18 years or younger. Past studies have demonstrated that MTurk is a cost-effective and reliable means of recruiting nationally representative samples of parents for online surveys [21]. We applied specific MTurk qualifications, stipulating that participants have a $98 \%$ approval rating on at least 100 prior HITs to qualify for this survey. Additionally, we applied custom qualifications to prevent multiple entries from the same individual. Eligible participants completed the survey through a web-link to Qualtrics survey software. Participants received $\$ 3.65$ for completing this 30-min task. All subjects gave their informed consent for inclusion before they participated in the study. The study was conducted in accordance with the Declaration of Helsinki, and the protocol was approved by the Ethics Committee of Washington University School of Medicine (202004198). Participants reviewed an exempt information sheet at the beginning of the survey indicating the purpose of the study, the identity of the researchers, and the anticipated time commitment. Data were stored on encrypted servers.

We administered this survey in two rounds to perform exploratory factor analysis (EFA) followed by confirmatory factor analysis (CFA). Round 1 collected 449 responses, and round 2 collected 451 responses. Surveys were opened on 23 April 2020 and 11 May 2020. For the AAIH-P measure, each screen of the questionnaire contained 6 to 8 items. In total, the full battery of surveys contained 14 screens of questions. We utilized forced entry, so no questionnaires were incomplete. Respondents were not able to review or change answers from prior screens. Completion rates were 449/508 (88\%) and 451/498 (91\%) for rounds 1 and 2, respectively.

For quality control, we excluded participants who completed the survey in less than $7 \mathrm{~min}$, anticipating that each question should require $4-5 \mathrm{~s}$ to respond meaningfully. For this reason, we excluded 20 participants $(4 \%)$ in the first round and $54(11 \%)$ in the second round. Additionally, we excluded 11 participants from each round who provided ages of children that were greater than 18 years. After exclusions, round 1 included 418 participants and round 2 included 386 participants, for a total of 804 participants in the entire study.

\subsection{Validity and Psychometric Properties of AAIH-P Measure}

To assess the validity of the AAIH-P openness measure, we assessed for internal reliability and convergent validity with other validated scales. To assess the validity of the AAIH-P concerns measure, we performed exploratory and confirmatory factor analysis.

\subsubsection{AAIH-P Openness Scale}

For the 12-item AAIH-P openness scale, we computed the mean response to items to create a composite score that ranged from 1 to 5 . To test for internal reliability, we calculated Cronbach's alpha for the full 12-item scale $(\alpha=0.92)$. We also calculated mean responses and Cronbach's alpha for the items related to the four different AI-driven healthcare functions: diagnosis $(\alpha=0.84)$, risk prediction $(\alpha=0.87)$, treatment selection $(\alpha=0.90)$, and medical guidance $(\alpha=0.84)$.

\subsubsection{Exploratory Factor Analysis}

We performed EFA with Promax rotation to assess the factor structure of the AAIH-P concerns scale. We examined the scree plot of eigenvalues and considered the amount of variance explained by each additional factor in order to determine the total number of factors to include. We also considered the number and magnitude of loadings on factors across potential factor solutions [22]. Factorability of the items was confirmed by a significant Bartlett's test of sphericity, v2 (1596) $=12,393.25, p<0.001$, and Kaiser-Meyer-Olkin value of greater than $0.6(\mathrm{KMO}=0.92)$. 
Results of the EFA indicated a seven-factor solution that accounted for $54 \%$ of variance. We dropped two items that loaded poorly on these seven factors, and we dropped 16 items because of significant cross-loading on other factors $(>0.3)$. To decrease survey burden, we dropped eight items with content that was captured in other similar items. After dropping these items, we repeated EFA with the 34 remaining items, finding that a seven-factor solution explained $60 \%$ of variance (see Table 1 for definitions of factors).

Table 1. Parental concerns with AI-driven healthcare technologies

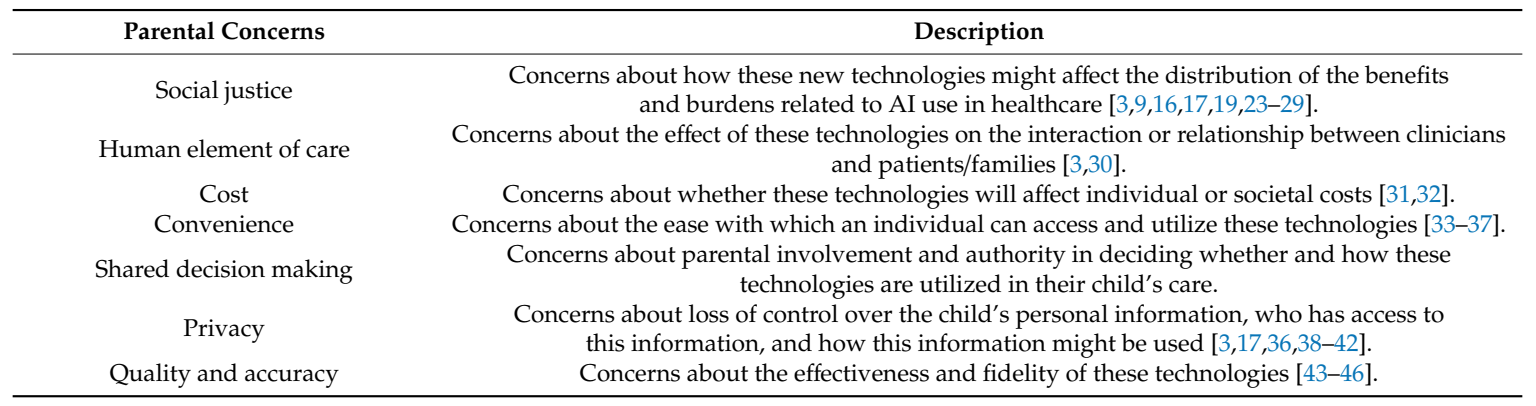

\subsubsection{Confirmatory Factor Analysis}

We then distributed the battery of surveys containing the revised 34-item AAIH-P concerns scale and performed CFA using maximum likelihood estimation. We allowed all factors to correlate with each other. We removed one item with poor fit. There was acceptable fit between the finalized model and the observed data: $\chi^{2} p<0.001, \mathrm{CFI}=0.91, \mathrm{RMR}=0.069, \mathrm{RMSEA}=0.053$.

\subsubsection{Measures of Sociodemographic Attributes, Attitudes, and Personality Traits}

To assess for convergent validity of the AAIH-P openness scale, we also administered measures of sociodemographic attributes, attitudes, and personality traits and examined associations with openness on AAIH-P. The Ten Item Personality Inventory (TIPI) is a 10-item measure used to assess personality constructs: openness to new experiences, conscientiousness, extraversion, agreeableness, and emotional stability [47]. We anticipated a positive relationship between AAIH-P openness scale and openness as a personality trait. We assessed participants' trust in health information systems using Platt's scale. This 20-item scale includes four subscales: Fidelity, Competency, Trust, and Integrity [48]. We also included a measure of faith and trust in general technology [49]. We hypothesized a positive correlation between measures of trust and openness scores on AAIH-P.

We asked participants which political party they most align with: Democrat, Republican, Independent, or other. For respondents who chose independent or other, we asked whether they leaned democrat or leaned republican. For analysis, we clustered democrat with lean democrat and republican with lean republican. We hypothesized that participants who align with the Republican Party would be more conservative and might have lower openness on AAIH-P.

Lastly, we included the Positive and Negative Affect Scale (PANAS) to assess for the impact of the participant's current affect on responses. This survey was administered during the early phases of the COVID-19 pandemic, and we hypothesized that negative affect generated by the societal challenges might negatively correlate with openness.

\subsection{Statistical Analyses}

We examined correlations between openness on AAIH-P and the other scales and demographic variables using Pearson (continuous variables) or Spearman (ordinal variables) correlations. To further explore the relationships between these variables and openness, we performed multiple linear regression with stepwise entry, excluding non-significant variables $(p<0.05)$. In the original model, we included the scores of all AAIH-P concerns subscales, race, and all other variables that demonstrated a significant 
correlation $(p<0.05)$ in bivariable correlations with openness. Given the number of included variables and potential for intercorrelation, we performed iterative calculations of variance inflation factor (VIF) to assess for multicollinearity. All VIFs were $<5$ and most were $<2$, indicating low likelihood of multicollinearity. We performed analyses in IBM SPSS statistical package v26.0.0.0, using Amos Structural Equation Modeling plug-in for CFA.

\section{Results}

\subsection{Participant Characteristics}

The majority of participants were female (59\%, 470/804), and the mean (M) age was $\mathrm{M}=38.9$, standard deviation (SD) $=8$ years. Most participants were non-Hispanic $(93 \%, 751 / 804)$ and White (86\%, 689/804). Additionally, $10 \%$ (77/804) were Black, 6\% (44/804) were Asian, and 3\% (20/804) were American Indian or Alaska Native. Most participants had completed a Bachelor's or graduate degree $(59 \%, 481 / 804)$. Participants had a median of 2 children, ranging from 1 to 8 . (Table 2).

Table 2. Participant characteristics

\begin{tabular}{|c|c|}
\hline Participant Characteristics $(N=804)$ & $n(\%)$, Except Where Specified \\
\hline Age of parent, Mean (SD) & 38.9 years $(8.0)$ \\
\hline Female sex & $470(59 \%)$ \\
\hline \multicolumn{2}{|l|}{ Race * } \\
\hline White & $689(86 \%)$ \\
\hline Black or African American & $77(10 \%)$ \\
\hline Asian & $44(6 \%)$ \\
\hline American Indian or Alaska Native & $20(3 \%)$ \\
\hline Native Hawaiian or Pacific Islander & $2(<1 \%)$ \\
\hline Hispanic ethnicity & $53(7 \%)$ \\
\hline \multicolumn{2}{|l|}{ Employment status } \\
\hline Full-time & $560(70 \%)$ \\
\hline Part-time (not a full-time student) & $48(6 \%)$ \\
\hline Full-time student & $2(<1 \%)$ \\
\hline Self-employed & $61(8 \%)$ \\
\hline Caregiver or homemaker & $93(11 \%)$ \\
\hline Other & $40(5 \%)$ \\
\hline \multicolumn{2}{|l|}{ Household income } \\
\hline Less than 23,000 & $42(5 \%)$ \\
\hline $23,001-45,000$ & $150(19 \%)$ \\
\hline $45,001-75,000$ & $263(32 \%)$ \\
\hline $75,001-112,000$ & $208(26 \%)$ \\
\hline Greater than 112,001 & $138(17 \%)$ \\
\hline \multicolumn{2}{|l|}{ Level of education } \\
\hline Some high school & $5(<1 \%)$ \\
\hline High school graduate & $61(8 \%)$ \\
\hline Some college & $141(18 \%)$ \\
\hline Associate's degree & $116(14 \%)$ \\
\hline Bachelor's degree & $343(42 \%)$ \\
\hline Master's or doctoral degree & $138(17 \%)$ \\
\hline \multicolumn{2}{|l|}{ Place of residence } \\
\hline Urban & $176(22 \%)$ \\
\hline Suburban & $460(57 \%)$ \\
\hline Rural & $168(21 \%)$ \\
\hline
\end{tabular}


Table 2. Cont.

\begin{tabular}{|c|c|}
\hline Participant Characteristics $(N=804)$ & $n(\%)$, Except Where Specified \\
\hline \multicolumn{2}{|l|}{ Health insurance status } \\
\hline Private & $595(74 \%)$ \\
\hline Medicaid & $116(14 \%)$ \\
\hline Medicare/Medicare Advantage & $47(6 \%)$ \\
\hline No health insurance & $30(4 \%)$ \\
\hline Other & $16(2 \%)$ \\
\hline Number of children, median (IQR) & 2 (1 to 2$)$ \\
\hline Child visited doctor in past 12 months & $709(88 \%)$ \\
\hline Number of doctor visits, median (IQR) & $8(6$ to 10$)$ \\
\hline Child hospitalized in past 12 months & $27(3 \%)$ \\
\hline Number of hospitalizations, median (IQR) & 1 (1 to 2$)$ \\
\hline
\end{tabular}

* Race responses were not mutually exclusive. Missing data due to selecting 'prefer not to answer': Sex (1), Race (5), Household Income (3), Level of Education (1), Political Alignment (1). SD = standard deviation. $\mathrm{IQR}=$ interquartile range.

\subsection{Openness to AI-Driven Healthcare Interventions and Parental Concerns}

Parents had a mean openness score on the AAIH-P of $\mathrm{M}=3.4$ (on a five-point scale), $\mathrm{SD}=0.9$. Openness to the four different AI-driven healthcare functions were as follows: diagnosis $\mathrm{M}=3.8$, $\mathrm{SD}=1.1$; risk prediction $\mathrm{M}=3.1, \mathrm{SD}=1.2$; treatment selection $\mathrm{M}=3.2, \mathrm{SD}=1.2$; medical guidance $\mathrm{M}=3.6, \mathrm{SD}=1.0 . \mathrm{EFA}$ and CFA identified seven concerns that parents considered important when evaluating the use of AI-driven healthcare interventions in their child's medical care. (Table 1) Quality $(\mathrm{M}=4.3, \mathrm{SD}=0.8)$, privacy $(\mathrm{M}=4.2, \mathrm{SD}=0.8)$, and shared decision making $(\mathrm{M}=4.1, \mathrm{SD}=0.8)$ received the highest mean importance ratings. Convenience $(\mathrm{M}=3.8, \mathrm{SD}=0.8)$, $\operatorname{cost}(\mathrm{M}=3.7, \mathrm{SD}=1.0)$, human element $(\mathrm{M}=3.5, \mathrm{SD}=0.9)$, and social justice $(\mathrm{M}=3.5, \mathrm{SD}=1.0)$ were rated lower.

\subsection{Relationships between Openness on AAIH-P and Parent Concerns and Characteristics}

Of the seven concerns identified in factor analysis, four concerns correlated significantly and positively with openness: social justice, quality, cost, and convenience. Measures of trust also correlated positively with openness: all Platt subscales, Faith in Technology, and Trust in Technology. Alignment with the Democratic Party or leaning toward the Democratic Party correlated positively with openness. Three personality traits correlated positively with AAIH-P openness: extroversion, openness to change, and emotional stability. Positive affect also correlated positively with openness. Of demographic variables, being female negatively correlated with openness (Table 3).

In multivariable linear regression, nine variables showed a significant association with parental openness to AI-driven interventions in their child's healthcare. Of concerns, quality ( $\beta=0.23,95 \%$ Confidence Interval (CI) 0.16 to 0.31 ), convenience ( $\beta=0.16,95 \%$ CI 0.09 to 0.23$)$, and cost ( $\beta=0.11$, $95 \%$ CI 0.04 to 0.17 ) were positively associated with openness. Shared decision making was negatively associated with openness ( $\beta=-0.16,95 \% \mathrm{CI}-0.23$ to -0.10$)$. Two measures of trust were positively associated with openness: Faith in Technology ( $\beta=0.23,95 \%$ CI 0.17 to 0.29$)$ and Platt Trust subscale ( $\beta=0.12,95 \%$ CI 0.06 to 0.18 ). Alignment with the Democratic Party $(\beta=0.09,95 \%$ CI 0.03 to 0.15$)$ and extroversion ( $\beta=0.04,95 \%$ CI 0.01 to 0.07 ) had small positive associations with openness, and being female had a negative association ( $\beta=-0.12,95 \%$ CI -0.18 to -0.06$)$ (Table 4$)$.

Although parents reported that privacy was highly important to them, privacy scores were not associated with openness scores. To further explore the role of privacy, we examined an exploratory multivariable model with openness as the dependent variable and the seven factors as predictor variables. In this model, privacy had a small, negative association with AAIH-P openness ( $\beta=-0.08$, $95 \%$ CI -0.155 to -0.01 ). We then explored the correlations between privacy and measures of trust, finding that privacy was negatively correlated with the trust subscale of the Platt measure $(\mathrm{r}=-0.10$, $p=0.03)$ and the trust in technology scale $(r=-0.11, p=0.002)$. 
Table 3. Bivariable correlations with openness to AI-driven interventions in pediatrics

\begin{tabular}{|c|c|}
\hline Variable (Cronbach's Alpha) & Correlation ( $p$ Value) \\
\hline \multicolumn{2}{|l|}{ Concerns } \\
\hline Social justice (0.86) & $0.22(<0.001)$ \\
\hline Human element (0.72) & $0.02(0.49)$ \\
\hline Cost $(0.81)$ & $0.25(0.001)$ \\
\hline Convenience (0.69) & $0.31(0.001)$ \\
\hline Shared decision making $(0.72)$ & $-0.01(0.84)$ \\
\hline Privacy $(0.87)$ & $-0.03(0.45)$ \\
\hline Quality (0.71) & $0.34(<0.001)$ \\
\hline \multicolumn{2}{|l|}{ Attitudes, Beliefs, and Personality Scales } \\
\hline Platt fidelity (0.71) & $0.11(0.002)$ \\
\hline Platt competency $(0.78)$ & $0.21(<0.001)$ \\
\hline Platt trust $(0.95)$ & $0.23(<0.001)$ \\
\hline Platt integrity $(0.85)$ & $0.20(<0.001)$ \\
\hline TIPI extroversion $(0.80)$ & $0.13(<0.001)$ \\
\hline TIPI openness $(0.59)$ & $0.13(<0.001)$ \\
\hline TIPI agreeableness (0.46) & $0.06(0.10)$ \\
\hline TIPI conscientiousness $(0.73)$ & $0.06(0.08)$ \\
\hline TIPI emotional stability $(0.83)$ & $0.10(0.01)$ \\
\hline Faith in technology $(0.87)$ & $0.36(<0.001)$ \\
\hline Trust in technology $(0.91)$ & $0.28(<0.001)$ \\
\hline PANAS-Positive affect $(0.91)$ & $0.17(<0.001)$ \\
\hline PANAS-Negative affect $(0.91)$ & $0.01(0.81)$ \\
\hline Democrat/lean Democrat political alignment & $0.09(0.015)$ \\
\hline \multicolumn{2}{|l|}{ Demographic Variables } \\
\hline Female sex & $-0.13(<0.001)$ \\
\hline Age & $-0.04(0.294)$ \\
\hline Race (White vs Person of Color) ${ }^{*}$ & $0.04(0.238)$ \\
\hline Ethnicity (Hispanic vs non-Hispanic) & $-0.04(0.248)$ \\
\hline Worked in healthcare field & $-0.01(0.780)$ \\
\hline Income & $0.03(0.357)$ \\
\hline Highest level of education & $0.03(0.468)$ \\
\hline Number of children & $-0.05(0.149)$ \\
\hline Number of children's doctor visits $* *$ & $-0.05(0.773)$ \\
\hline Child hospitalization & $<0.01(0.889)$ \\
\hline
\end{tabular}

We used Spearman correlation for concerns and all demographic variables except age. Bolding indicates $p<0.05$. We used Pearson correlation for all remaining correlations. ${ }^{*}$ Participants who selected any race category other than White or in addition to White were considered "Persons of Color" in this analysis. ** Excluded 98 responses of parents whose children had no doctor's visits. TIPI $=$ Ten Item Personality Inventory. PANAS = Positive and Negative Affect Scale.

Table 4. Multivariable model of variables associated with openness to AI-driven interventions in pediatric healthcare

\begin{tabular}{lcc}
\hline \multicolumn{1}{c}{ Variable } & $\begin{array}{c}\text { Standardized } \\
\beta \text { Coefficient }(\mathbf{9 5 \%} \text { CI) }\end{array}$ & $p$ Value \\
\hline Concerns & $0.23(0.16$ to 0.31$)$ & $<0.001$ \\
Quality & $0.16(0.09$ to 0.23$)$ & $<0.001$ \\
Convenience & $0.11(0.04$ to 0.17$)$ & 0.001 \\
Cost & $-0.16(-0.23$ to -0.10$)$ & $<0.001$ \\
Shared decision making & $0.23(0.17$ to 0.29$)$ & $<0.001$ \\
Attitudes, Beliefs, and Personality Scales & $<0.001$ \\
Faith in technology & $0.12(0.06$ to 0.18$)$ & 0.002 \\
Platt trust & $0.09(0.03$ to 0.15$)$ & 0.015 \\
Democrat/lean Democrat & $0.04(0.01$ to 0.07$)$ & $<0.001$ \\
TIPI extroversion & $-0.12(-0.18$ to -0.06$)$ & \\
Demographic Variables & Female sex &
\end{tabular}

Multiple linear regression with stepwise entry. We initially included scores of all concern subscales, all other variables with significant correlation to openness and race. 


\section{Discussion}

In this study, we developed the first measure of openness to AI-driven healthcare interventions in pediatrics. Our study provided evidence of face, content, and construct validity for this measure of openness, as well as factorial validity for the measure of concerns. In administration to 804 participants, we found that parents were moderately open to the use of AI-driven healthcare interventions in their child's medical care. We also identified seven categories of concerns that parents found important in considering the use of these technologies. These results reinforce prior findings from the Future Advocacy initiative, in which researchers interviewed 71 professionals with experience in $\mathrm{AI}$ and 16 members of the public to identify potential ethical, social, and political implications of $\mathrm{AI}$ in healthcare. The authors identified issues related to the impact of AI on human relationships in health and care, storage and sharing of medical data, algorithmic transparency/explainability, health-related disparities, and trustworthiness or reliability of these interventions, among others [3]. Others have similarly highlighted concerns about privacy, transparency, and the role of the physician as AI-driven interventions become incorporated into medical practice [50,51]. However, ours is the first study to verify the importance of these issues to parents in a large, quantitative survey.

On average, parents considered each of these concerns to be important or very important. In a multivariable model, quality of the intervention, convenience, and cost were positively associated with openness. Given this positive association, it is possible that parents who are more open to these technologies believe that AI-driven technologies will improve the cost, quality, and convenience of pediatric healthcare. Conversely, parents who rated shared decision making highly were less likely to be open. This finding suggests that some parents worry these technologies might decrease their role in making decisions on behalf of their child. Several studies have identified "making informed decisions" as central to "good parenting" beliefs for parents of seriously ill children [52-56]. By ensuring that new technologies engage parents in the decision-making process, researchers and developers might enhance parental openness to using these technologies in their child's care. Beyond these factors, parental reports of faith in technology and trust in public health information sharing were also associated with openness.

Interestingly, the privacy subscale was not associated with parental openness to these technologies, despite parents rating privacy items as highly important. In exploratory analyses, we found that privacy scores correlated negatively with trust scales. Furthermore, we found that privacy scores were significantly associated with openness when we excluded trust scores from the multivariable model. These findings suggest that privacy and trust scales are measuring similar underlying constructs. If parents have lower trust, then they will tend to be more concerned about privacy. As such, privacy concerns might affect openness to the extent that they change the parent's level of trust. However, these findings were exploratory, and the role of privacy concerns should be more fully explored in future studies.

These findings provide important insights into parental openness to AI-driven healthcare for their children, and they indicate several characteristics of parents and interventions that might affect this openness. AI researchers and developers should consider these variables when designing and implementing novel interventions. By addressing these ethical and practical concerns early in the development process, parents might be more likely to engage with precision medicine research and applications. Without this engagement, children might be left behind as precision medicine advances in other disciplines. 
These results, however, should be interpreted in light of limitations. First, parents in this sample were predominantly White with college education. Given the concern that precision medicine could exacerbate racial and socio-economic disparities [57,58], future studies should engage with medically underserved communities to ensure adequate representation of their values and beliefs. Additionally, only $3 \%$ of parents reported that their children had been hospitalized in the last 12 months. Future studies should engage parents of children with serious illnesses to explore the impact of children's health status on parental openness. Also, this survey was administered through MTurk to participants who are likely comfortable with technology. As such, the openness of this sample could be skewed to more openness to novel technologies, potentially limiting the generalizability of these results. This sample was also skewed toward higher education and income. However, our sample was large, we did have adequate numbers of people in the lower education and income categories to detect modest differences. There were no significant differences or trends in the data. We believe this reduces the negative effect of this demographic skew on our conclusions. Lastly, we only identified concerns that were in our original framework. While our cognitive interviews provided important insights, our study could have been strengthened by more qualitative work with parents to potentially identify additional of concerns related to AI in their child's healthcare. Future explanatory mixed-methods studies should explore whether parents have additional concerns not represented in this measure.

AI-driven precision medicine could transform pediatric care in the future. However, development of these technologies requires analysis of large amounts of data from many children. Thus, parental openness to the use of these AI-driven technologies in their child's care is paramount. In this study, we developed and validated a novel measure of parental openness to the use of AI-driven precision medicine interventions in their child's care. We also found that parental openness is associated with perceptions of the intervention's impact on cost, quality, convenience, and shared decision making, as well as trust in information sharing systems, faith in technology, and the parents' gender. These findings can inform strategies for intervention development and engagement with parents in the future.

Author Contributions: Conceptualization, B.A.S., A.L.A., S.B., and J.M.D.; Methodology, B.A.S., A.L.A., S.B., and J.M.D.; Investigation, B.A.S., A.L.A., and S.B.; Funding acquisition, B.A.S., A.L.A., and J.M.D.; Data curation, B.A.S.; Formal analysis, B.A.S.; Writing first draft, B.A.S. and S.B.; Reviewing and/or editing the manuscript, S.B., A.L.A., and J.M.D. All authors have read and agreed to the published version of the manuscript.

Funding: This research was funded by National Center for Advancing Translational Sciences of the National Institutes of Health (UL1 TR002345) and National Human Genome Research Institute (K01HG008990).

Acknowledgments: Thank you to Romario Smith for his support in cognitive interviewing and survey development.

Conflicts of Interest: The authors declare no conflict of interest. The funders had no role in the design of the study; in the collection, analyses, or interpretation of data; in the writing of the manuscript, or in the decision to publish the results. 


\section{Appendix A}



Checklist for Reporting Results of Internet E-Surveys (CHERRIES)

\begin{tabular}{l} 
Item Category \\
\hline Design \\
IRB (Institutional Review \\
Board) approval and informed \\
consent process
\end{tabular}

Explanation

Describe survey design

Describe target population, sample frame. Is the sample a convenience sample? (In "open" surveys this is most likely.)

consent process

IRB approval

Development and pre-testing

Development and testing

Recruitment process and description of the sample having access to the questionnaire

\section{Survey administration}

Web/E-mail

Context
Open survey versus closed survey

Contact mode

Advertising the survey
An "open survey" is a survey open for each visitor of a site, while a closed survey is only open to a sample which the investigator knows (password-protected survey).

Indicate whether or not the initial contact with the potential participants was made on the Internet. (Investigators may also send out questionnaires by mail and allow for Web-based data entry.)

How/where was the survey announced or advertised? Some examples are offline media (newspapers), or online (mailing lists - If yes, which ones?) or banner ads (Where were these banner ads posted and what did they look like?). It is important to know the wording of the announcement as it will heavily influence who chooses to participate. Ideally the survey announcement should be published as an appendix.

State the type of e-survey (eg, one posted on a Web site, or one sent out through e-mail). If it is an e-mail survey, were the responses entered manually into a database, or was there an automatic method for capturing responses?

Describe the Web site (for mailing list'newsgroup) in which the survey was posted. What is the Web site about, who is visiting it, what are visitors normally looking for? Discuss to what degree the content of the Web site could pre-select the sample or influence the results. For example, a survey about vaccination on a anti-immunization Web site will have different results from a Web survey conducted on a government Web site

Was it a mandatory survey to be filled in by every visitor who wanted to enter the Web site, or was it a voluntary survey?

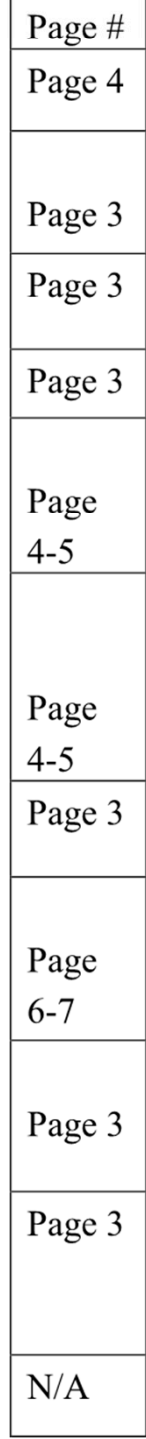

Figure A1. Cont. 
Checklist Item

Incentives

Time/Date

Randomization of items of questionnaires

Adaptive questioning

Number of Items

Number of screens (pages)

Completeness check

Review step

Response rates

Preventing multiple entries from the same individual

Cookies used page visitors) whe agreed to
Explanation

Were any incentives offered (eg, monetary, prizes, or non-monetary incentives such as an offer to provide the survey results)?

In what timeframe were the data collected?

To prevent biases items can be randomized or alternated.

Use adaptive questioning (certain items, or only conditionally displayed based on responses to other items) to reduce number and complexity of the questions. What was the number of questionnaire items per page? The number of items is an important factor for the completion rate.

Over how many pages was the questionnaire distributed? The number of items is an important factor for the completion rate.

It is technically possible to do consistency or completeness checks before the questionnaire is submitted. Was this done, and if "yes", how (usually

JAVAScript)? An alternative is to check for completeness after the questionnaire has been submitted (and highlight mandatory items). If this has been done, it should be reported. All items should provide a non-response option such as " aplicable" or "rather not say", and selection of one response option sos "not enforced.

State whether respondents were able to review and change their answers (eg. through a Back button or a Review step which displays a summary of the responses and asks the respondents if they are correct).

If you provide view rates or participation rates, you need to define how you determined a unique visitor. There are different techniques available, based on IP addresses or cookies or both.

View rate (Ratio of unique sur- Requires counting unique visitors to the first page of the survey, divided by the vey visitors funique site visitors) number of unique site visitors (not page views!). It is not unusual to have view rates of less than $0.1 \%$ if the survey is voluntary.

Participation rate (Ratio of Count the unique number of people who filled in the first survey page (or agreed unique visitors who agreed to to participate, for example by checking a checkbox), divided by visitors who participate/unique first survey visit the first page of the survey (or the informed consents page, if present). This

can also be called "recruitment" rate.

Completion rate (Ratio of users The number of people submitting the last questionnaire page, divided by the who finished the survey/users number of people who agreed to participate (or submitted the first survey page).

number of people who agreed to participate (or submitted the first survey page).
This is only relevant if there is a separate "informed consent" page or if the This is only relevant if there is a separate "informed consent" page or if the
survey goes over several pages. This is a measure for attrition. Note that "com survey goes over several pages. This is a measure for attrition. Note that "com-
pletion" can involve leaving questionnaire items blank. This is not a measure pletion" can involve leaving questionnaire items blank. This is not a measure
for how completely questionnaires were filled in. (If you need a measure for this, use the word "completeness rate".)

Indicate whether cookies were used to assign a unique user identifier to each client computer. If so, mention the page on which the cookie was set and read, and how long the cookie was valid. Were duplicate entries avoided by preventing and how long the cookie was valid. Were duplicate entries avoided by preventing users access to the survey twice; or were duplicate database entries having the
same user ID eliminated before analysis? In the latter case, which entries were kept for analysis (eg, the first entry or the most recent)?

\section{Explanation}

Item Category Checklist Item

Indicate whether the IP address of the client computer was used to identify potential duplicate entries from the same user If so, mention the period of time for which no two entries from the same IP address were allowed (eg, 24 hours). Were duplicate entries avoided by preventing users with the same IP address access to the survey twice; or were duplicate database entries having the same access to the survey twice; or were duplicate database entries having the same IP address within a given period of time eliminated before analysis? If the later,
which entries were kept for analysis (eg, the first entry or the most recent)?

Log file analysis

Indicate whether other techniques to analyze the log file for identification of multiple entries were used. If so, please describe.

Registration

In "closed" (non-open) surveys, users need to login first and it is easier to prevent duplicate entries from the same user. Describe how this was done. For example, was the survey never displayed a second time once the user had filled it in, or was the username stored together with the survey results and later eliminated? If the latter, which entries were kept for analysis (eg, the first entry or the mos recent)?

Analysis

Handling of incomplete questionnaires

Were only completed questionnaires analyzed? Were questionnaires which tertex me, users did not go through all question pages) also analyzed?

Questionnaires submitted with Some investigators may measure the time people needed to fill in a questionnair an atypical timestamp and exclude questionnaires that were submitted too soon. Specify the timefrane that was used as a cut-off point, and describe how this point was determined.

Statistical correctio

Indicate whether any methods such as weighting of items or propensity scores have been used to adjust for the non-representative sample; if so, please describe the methods.

Page 3

Page 3

N/A

N/A

Page 3

Page 3

N/A

Page 3

N/A

N/A

N/A

Page 3

Page 3

N/A

N/A

N/A

Page 3

Page 3

N/A

Figure A1. Cherries Checklist. 


\section{Appendix B Full AAIH-P Measure with Factors Labeled}

Introduction: Overview: In this survey, we describe healthcare devices that use advanced computer programs. Some of the devices already exist. Others might soon exist. These devices are becoming common. We want to know your views about them. There are no right or wrong answers.

\begin{tabular}{|c|c|c|c|c|c|}
\hline \multirow{2}{*}{$\begin{array}{l}\text { How Open Are You to Allowing Computer Programs to Do the Following Things? } \\
\text { (1) Determine if your child has an ear infection. }\end{array}$} & \multicolumn{5}{|c|}{ Please Rate Your Response for Each Statement } \\
\hline & 1 & 2 & 3 & 4 & 5 \\
\hline (2) Determine if your child broke a bone. & 1 & 2 & 3 & 4 & 5 \\
\hline (3) Determine if your child has cancer. & 1 & 2 & 3 & 4 & 5 \\
\hline (4) Predict your child's risk of developing obesity in the future. & 1 & 2 & 3 & 4 & 5 \\
\hline (5) Predict your child's risk of developing depression in the future. & 1 & 2 & 3 & 4 & 5 \\
\hline (6) Predict your child's chances of developing a disease that cannot be cured. & 1 & 2 & 3 & 4 & 5 \\
\hline (7) Decide on the best treatment for your child's lung infection. & 1 & 2 & 3 & 4 & 5 \\
\hline (8) Decide how often your child needs pain medication after surgery. & 1 & 2 & 3 & 4 & 5 \\
\hline (9) Decide the best treatment for your child's diabetes. & 1 & 2 & 3 & 4 & 5 \\
\hline (10) Give your child feedback on how to prevent anxiety attacks. & 1 & 2 & 3 & 4 & 5 \\
\hline (11) Recommend if you should bring your child to the hospital after an injury. & 1 & 2 & 3 & 4 & 5 \\
\hline (12) Give you advice on how to prevent your child's asthma attacks. & 1 & 2 & 3 & 4 & 5 \\
\hline
\end{tabular}

1-Not at all open, 2-Somewhat open, 3-Open, 4-Very open, 5-Extremely open.

Many things are important when considering whether to use these new devices in your child's medical care. We want to understand which things are most important to you, and which things are the least important to you. In the next set of questions, please pick the response that best matches your feelings about these devices.

\begin{tabular}{|c|c|c|c|c|c|}
\hline \multirow{2}{*}{$\begin{array}{c}\text { When You Think of Using These New Devices, How Important Are the Following Details to You? } \\
\text { (1) Whether these devices help you to weigh the risks and benefits of different treatment options for your } \\
\text { child's illness. (Quality and Accuracy) }\end{array}$} & \multicolumn{5}{|c|}{ Please Rate Your Response for Each Statement } \\
\hline & 1 & 2 & 3 & 4 & 5 \\
\hline $\begin{array}{l}\text { (2) Whether companies that develop these devices share your child's information with other } \\
\text { companies. (Privacy) }\end{array}$ & 1 & 2 & 3 & 4 & 5 \\
\hline (3) Whether these devices are available to low income families. (Social Justice) & 1 & 2 & 3 & 4 & 5 \\
\hline $\begin{array}{l}\text { (4) Whether these devices allow your child's doctor to spend more time with you during clinic visits. } \\
\text { (Human Element) }\end{array}$ & 1 & 2 & 3 & 4 & 5 \\
\hline (5) Whether these devices reduce medical errors. (Quality and Accuracy) & 1 & 2 & 3 & 4 & 5 \\
\hline (6) Whether you might save money by using these devices in your child's medical care. (Cost) & 1 & 2 & 3 & 4 & 5 \\
\hline $\begin{array}{l}\text { (7) Whether these devices make it harder to have a personal relationship with your child's doctor. } \\
\text { (Human Element) }\end{array}$ & 1 & 2 & 3 & 4 & 5 \\
\hline (8) Whether these devices provide information that is easy to understand. (Quality and Accuracy) & 1 & 2 & 3 & 4 & 5 \\
\hline (9) Whether families without health insurance can access these devices. (Social Justice) & 1 & 2 & 3 & 4 & 5 \\
\hline (10) Whether families in rural areas can access these devices. (Social Justice) & 1 & 2 & 3 & 4 & 5 \\
\hline (11) Whether you will have to pay extra to use these devices for your child's medical care. (Cost) & 1 & 2 & 3 & 4 & 5 \\
\hline $\begin{array}{c}\text { (12) Whether these devices reduce the wait time to schedule an appointment with your child's } \\
\text { doctor. (Convenience) }\end{array}$ & 1 & 2 & 3 & 4 & 5 \\
\hline $\begin{array}{l}\text { (13) Whether these devices make it easier to have a personal relationship with your child's doctor. } \\
\text { (Human Element) }\end{array}$ & 1 & 2 & 3 & 4 & 5 \\
\hline $\begin{array}{l}\text { (14) Whether your child's doctor asks you for permission before using these devices in your child's } \\
\text { medical care. (Shared Decision Making) }\end{array}$ & 1 & 2 & 3 & 4 & 5 \\
\hline $\begin{array}{c}\text { (15) Whether the doctor asks your opinion before prescribing the treatments recommended by these } \\
\text { devices. (Shared Decision Making) }\end{array}$ & 1 & 2 & 3 & 4 & 5 \\
\hline (16) Whether these devices are accurate. (Quality and Accuracy) & 1 & 2 & 3 & 4 & 5 \\
\hline $\begin{array}{l}\text { (17) Whether you know how your child's medical information will be used by the company that owns } \\
\text { this technology. (Privacy) }\end{array}$ & 1 & 2 & 3 & 4 & 5 \\
\hline $\begin{array}{l}\text { (18) Whether you are better able to prevent your child from getting sick because of these devices. } \\
\text { (Quality and Accuracy) }\end{array}$ & 1 & 2 & 3 & 4 & 5 \\
\hline $\begin{array}{c}\text { (19) Whether you can get your child's medical test results more quickly because of these } \\
\text { devices. (Convenience) }\end{array}$ & 1 & 2 & 3 & 4 & 5 \\
\hline (20) Whether your insurance costs will increase to pay for these devices. (Cost) & 1 & 2 & 3 & 4 & 5 \\
\hline (21) Whether these devices are widely available to everyone. (Social Justice) & 1 & 2 & 3 & 4 & 5 \\
\hline (22) Whether these devices will store pictures of your child in an online database. (Privacy) & 1 & 2 & 3 & 4 & 5 \\
\hline (23) Whether these devices can answer your healthcare questions. (Quality and Accuracy) & 1 & 2 & 3 & 4 & 5 \\
\hline (24) Whether these devices will increase costs to the overall healthcare system. (Cost) & 1 & 2 & 3 & 4 & 5 \\
\hline (25) Whether people living with disabilities can access these devices. (Social Justice) & 1 & 2 & 3 & 4 & 5 \\
\hline (26) Whether computer hackers could steal your child's medical information from these devices. (Privacy) & 1 & 2 & 3 & 4 & 5 \\
\hline $\begin{array}{l}\text { (27) Whether these devices are equally accurate when used for people of different races and ethnicities. } \\
\text { (Social Justice) }\end{array}$ & 1 & 2 & 3 & 4 & 5 \\
\hline
\end{tabular}


(28) Whether the company collects more information than it needs about your child. (Privacy) (29) Whether your child's medical information is kept private. (Privacy)

(30) Whether your child's doctor tells you if these devices are used in your child's care. (Shared Decision Making)

(31) Whether these devices help your child get medical care with fewer doctor visits. (Convenience)

(32) Whether the doctor orders the treatments recommended by these devices without first asking your opinion. (Shared Decision Making)

(33) Whether a computer will answer most of your questions instead of people. (Human Element)

1-Not Important, 2—Somewhat Important, 3-Important, 4-Very Important, 5-Extremely Important.

Note: Items are labeled with the subscale they are measuring (e.g. 'human element', 'privacy', et al.) for the convenience of the reader. These italicized labels should not be included when the measure is administered to parents.

\section{References}

1. Aronson, S.J.; Rehm, H.L. Building the foundation for genomics in precision medicine. Nature 2015, 526, 336-342. [CrossRef] [PubMed]

2. Sankar, P.L.; Parker, L.S. The Precision Medicine Initiative's All of Us Research Program: An agenda for research on its ethical, legal, and social issues. Genet. Med. Off. J. Am. Coll. Med. Genet. 2017, 19, 743-750. [CrossRef] [PubMed]

3. Fenech, M.; Strukelj, N.; Buston, O. Ethical, Social, and Political Challenges of Artificial Intelligence in Health; Future Advocacy: London, UK, 2018.

4. Jiang, F.; Jiang, Y.; Zhi, H.; Dong, Y.; Li, H.; Ma, S.; Wang, Y.; Dong, Q.; Shen, H.; Wang, Y. Artificial intelligence in healthcare: Past, present and future. Stroke Vasc. Neurol. 2017, 2, 230. [CrossRef] [PubMed]

5. Rajkomar, A.; Dean, J.; Kohane, I. Machine Learning in Medicine. N. Engl. J. Med. 2019, 380, 1347-1358. [CrossRef] [PubMed]

6. Burgess, M. Now DeepMind's AI can spot eye disease just as well as your doctor. WIRED, 13 August 2018.

7. Dolins, S.B.; Kero, R.E. The role of AI in building a culture of partnership between patients and providers. In Proceedings of the AAAI Spring Symposium-Technical Report, Stanford, CA, USA, 27-29 March 2006; pp. 47-51.

8. Li, D.; Kulasegaram, K.; Hodges, B.D. Why We Needn't Fear the Machines: Opportunities for Medicine in a Machine Learning World. Acad. Med. 2019, 94, 623-625. [CrossRef]

9. Topol, E.J. High-performance medicine: The convergence of human and artificial intelligence. Nat. Med. 2019, 25, 44-56. [CrossRef]

10. Chung, W.K.; Erion, K.; Florez, J.C.; Hattersley, A.T.; Hivert, M.F.; Lee, C.G.; McCarthy, M.I.; Nolan, J.J.; Norris, J.M.; Pearson, E.R.; et al. Precision Medicine in Diabetes: A Consensus Report From the American Diabetes Association (ADA) and the European Association for the Study of Diabetes (EASD). Diabetes Care 2020, 43, 1617-1635. [CrossRef]

11. Perez-Garcia, J.; Herrera-Luis, E.; Lorenzo-Diaz, F.; González, M.; Sardón, O.; Villar, J.; Pino-Yanes, M. Precision Medicine in Childhood Asthma: Omic Studies of Treatment Response. Int. J. Mol. Sci. 2020, 21, 2908. [CrossRef]

12. Vo, K.T.; Parsons, D.W.; Seibel, N.L. Precision Medicine in Pediatric Oncology. Surg. Oncol. Clin. N. Am. 2020, 29, 63-72. [CrossRef]

13. Verghese, A.; Shah, N.H.; Harrington, R.A. What This Computer Needs Is a Physician: Humanism and Artificial Intelligence. JAMA 2018, 319, 19-20. [CrossRef]

14. Eysenbach, G. Improving the quality of Web surveys: The Checklist for Reporting Results of Internet E-Surveys (CHERRIES). J. Med. Internet Res. 2004, 6, e34. [CrossRef] [PubMed]

15. Luxton, D.D. Recommendations for the ethical use and design of artificial intelligent care providers. Artif. Intell. Med. 2014, 62, 1-10. [CrossRef] [PubMed]

16. Char, D.S.; Shah, N.H.; Magnus, D. Implementing Machine Learning in Health Care-Addressing Ethical Challenges. N. Engl. J. Med. 2018, 378, 981-983. [CrossRef] [PubMed]

17. Vayena, E.; Blasimme, A.; Cohen, I.G. Machine learning in medicine: Addressing ethical challenges. PLoS Med. 2018, 15, e1002689. [CrossRef]

18. McDougall, R.J. Computer knows best? the need for value-flexibility in medical AI. J. Med. Ethics 2019, 45, 156-160. [CrossRef] 
19. Reddy, S.; Allan, S.; Coghlan, S.; Cooper, P. A governance model for the application of AI in health care. J. Am. Med. Inf. Assoc. 2019. [CrossRef]

20. Peterson, C.H.; Peterson, N.A.; Powell, K.G. Cognitive Interviewing for Item Development: Validity Evidence Based on Content and Response Processes. Meas. Eval. Couns. Dev. 2017, 50, 217-223. [CrossRef]

21. Dworkin, J.; Hessel, H.; Gliske, K.; Rudi, J.H. A Comparison of Three Online Recruitment Strategies for Engaging Parents. Fam. Relat. 2016, 65, 550-561. [CrossRef]

22. Clark, L.A.; Watson, D. Constructing validity: Basic issues in objective scale development. Psychol. Assess. 1995, 7, 309-319. [CrossRef]

23. Ferryman, K.; Winn, R.A. Artificial Intelligence Can Entrench Disparities-Here's What We Must Do; The Cancer Letter: Washington, DC, USA, 2018.

24. Gianfrancesco, M.A.; Tamang, S.; Yazdany, J.; Schmajuk, G. Potential Biases in Machine Learning Algorithms Using Electronic Health Record Data. JAMA Intern. Med. 2018, 178, 1544-1547. [CrossRef]

25. Nordling, L. A fairer way forward for AI in health care. Nature 2019, 573, S103-S105. [CrossRef] [PubMed]

26. Adamson, A.S.; Smith, A. Machine Learning and Health Care Disparities in Dermatology. JAMA Dermatol. 2018, 154, 1247-1248. [CrossRef] [PubMed]

27. Carter, S.M.; Rogers, W.; Win, K.T.; Frazer, H.; Richards, B.; Houssami, N. The ethical, legal and social implications of using artificial intelligence systems in breast cancer care. Breast 2020, 49, 25-32. [CrossRef]

28. Shaw, J.; Rudzicz, F.; Jamieson, T.; Goldfarb, A. Artificial Intelligence and the Implementation Challenge. J. Med. Internet Res. 2019, 21, e13659. [CrossRef] [PubMed]

29. Yu, K.H.; Kohane, I.S. Framing the challenges of artificial intelligence in medicine. BMJ Qual. Saf. 2019, 28, 238-241. [CrossRef]

30. Mukherjee, S.A.I.; Versus, M.D. Available online: http://www.medi.io/blog/2017/4/ai-versus-md-new-yorker (accessed on 18 September 2020).

31. Emanuel, E.J.; Wachter, R.M. Artificial Intelligence in Health Care: Will the Value Match the Hype? JAMA J. Am. Med. Assoc. 2019, 321, 2281-2282. [CrossRef]

32. Maddox, T.M.; Rumsfeld, J.S.; Payne, P.R.O. Questions for Artificial Intelligence in Health Care. JAMA J. Am. Med. Assoc. 2019, 321, 31-32. [CrossRef]

33. Esteva, A.; Kuprel, B.; Novoa, R.A.; Ko, J.; Swetter, S.M.; Blau, H.M.; Thrun, S. Dermatologist-level classification of skin cancer with deep neural networks. Nature 2017, 542, 115-118. [CrossRef]

34. Lopez-Garnier, S.; Sheen, P.; Zimic, M. Automatic diagnostics of tuberculosis using convolutional neural networks analysis of MODS digital images. PLoS ONE 2019, 14. [CrossRef]

35. Uthoff, R.D.; Song, B.; Sunny, S.; Patrick, S.; Suresh, A.; Kolur, T.; Keerthi, G.; Spires, O.; Anbarani, A.; Wilder-Smith, P.; et al. Point-of-care, smartphone-based, dual-modality, dual-view, oral cancer screening device with neural network classification for low-resource communities. PLoS ONE 2018, 13. [CrossRef]

36. Tran, V.-T.; Riveros, C.; Ravaud, P. Patients' views of wearable devices and AI in healthcare: Findings from the ComPaRe e-cohort. NPJ Digit. Med. 2019, 2, 53. [CrossRef] [PubMed]

37. Tsay, D.; Patterson, C. From Machine Learning to Artificial Intelligence Applications in Cardiac Care. Circulation 2018, 138, 2569-2575. [CrossRef] [PubMed]

38. Balthazar, P.; Harri, P.; Prater, A.; Safdar, N.M. Protecting Your Patients' Interests in the Era of Big Data, Artificial Intelligence, and Predictive Analytics. J. Am. Coll. Radiol. 2018, 15, 580-586. [CrossRef] [PubMed]

39. Price, W.N. Big data and black-box medical algorithms. Sci. Transl. Med. 2018, 10. [CrossRef] [PubMed]

40. Price, W.N. Artificial intelligence in Health Care: Applications and Legal Implications. Scitech Lawyer 2017, 14.

41. Price, W.N.; Cohen, I.G. Privacy in the age of medical big data. Nat. Med. 2019, 25, 37-43. [CrossRef]

42. Reddy, S.; Fox, J.; Purohit, M.P. Artificial intelligence-enabled healthcare delivery. J. R. Soc. Med. 2019, 112, 22-28. [CrossRef]

43. Fujisawa, Y.; Otomo, Y.; Ogata, Y.; Nakamura, Y.; Fujita, R.; Ishitsuka, Y.; Watanabe, R.; Okiyama, N.; Ohara, K.; Fujimoto, M. Deep-learning-based, computer-aided classifier developed with a small dataset of clinical images surpasses board-certified dermatologists in skin tumour diagnosis. Br. J. Dermatol. 2019, 180, 373-381. [CrossRef]

44. Haenssle, H.A.; Fink, C.; Schneiderbauer, R.; Toberer, F.; Buhl, T.; Blum, A.; Kalloo, A.; Ben Hadj Hassen, A.; Thomas, L.; Enk, A.; et al. Man against Machine: Diagnostic performance of a deep learning convolutional 
neural network for dermoscopic melanoma recognition in comparison to 58 dermatologists. Ann. Oncol. 2018, 29, 1836-1842. [CrossRef]

45. Raumviboonsuk, P.; Krause, J.; Chotcomwongse, P.; Sayres, R.; Raman, R.; Widner, K.; Campana, B.J.L.; Phene, S.; Hemarat, K.; Tadarati, M.; et al. Deep learning versus human graders for classifying diabetic retinopathy severity in a nationwide screening program. NPJ Digit. Med. 2019, 2, 25. [CrossRef]

46. Urban, G.; Tripathi, P.; Alkayali, T.; Mittal, M.; Jalali, F.; Karnes, W.; Baldi, P. Deep Learning Localizes and Identifies Polyps in Real Time With 96\% Accuracy in Screening Colonoscopy. Gastroenterology 2018, 155, 1069-1078.e8. [CrossRef] [PubMed]

47. Buhrmester, M.; Kwang, T.; Gosling, S.D. Amazon's Mechanical Turk:A New Source of Inexpensive, Yet High-Quality, Data? Perspect. Psychol. Sci. 2011, 6, 3-5. [CrossRef] [PubMed]

48. Platt, J.E.; Jacobson, P.D.; Kardia, S.L.R. Public Trust in Health Information Sharing: A Measure of System Trust. Health Serv. Res. 2018, 53, 824-845. [CrossRef] [PubMed]

49. McKnight, D.H.; Choudhury, V.; Kacmar, C. Developing and Validating Trust Measures for e-Commerce: An Integrative Typology. Inf. Sys. Res. 2002, 13, 334-359. [CrossRef]

50. Cabitza, F.; Rasoini, R.; Gensini, G.F. Unintended Consequences of Machine Learning in Medicine. JAMA 2017, 318, 517-518. [CrossRef]

51. Rigby, M.J. Ethical Dimensions of Using Artificial Intelligence in Health Care. AMA J. Ethics 2019, 21, E121-E124.

52. Weaver, M.S.; October, T.; Feudtner, C.; Hinds, P.S. “Good-Parent Beliefs”: Research, Concept, and Clinical Practice. Pediatrics 2020. [CrossRef]

53. Hill, D.L.; Faerber, J.A.; Li, Y.; Miller, V.A.; Carroll, K.W.; Morrison, W.; Hinds, P.S.; Feudtner, C. Changes Over Time in Good-Parent Beliefs Among Parents of Children With Serious Illness: A Two-Year Cohort Study. J. Pain Symptom Manag. 2019, 58, 190-197. [CrossRef]

54. Feudtner, C.; Walter, J.K.; Faerber, J.A.; Hill, D.L.; Carroll, K.W.; Mollen, C.J.; Miller, V.A.; Morrison, W.E.; Munson, D.; Kang, T.I.; et al. Good-parent beliefs of parents of seriously ill children. JAMA Pediatr. 2015, 169, 39-47. [CrossRef]

55. October, T.W.; Fisher, K.R.; Feudtner, C.; Hinds, P.S. The parent perspective: "being a good parent" when making critical decisions in the PICU. Pediatr. Crit. Care Med. 2014, 15, 291-298. [CrossRef]

56. Hinds, P.S.; Oakes, L.L.; Hicks, J.; Powell, B.; Srivastava, D.K.; Baker, J.N.; Spunt, S.L.; West, N.K.; Furman, W.L. Parent-clinician communication intervention during end-of-life decision making for children with incurable cancer. J. Palliat. Med. 2012, 15, 916-922. [CrossRef] [PubMed]

57. Yeh, V.M.; Bergner, E.M.; Bruce, M.A.; Kripalani, S.; Mitrani, V.B.; Ogunsola, T.A.; Wilkins, C.H.; Griffith, D.M. Can Precision Medicine Actually Help People Like Me? African American and Hispanic Perspectives on the Benefits and Barriers of Precision Medicine. Ethn. Dis. 2020, 30, 149-158. [CrossRef] [PubMed]

58. Geneviève, L.D.; Martani, A.; Shaw, D.; Elger, B.S.; Wangmo, T. Structural racism in precision medicine: Leaving no one behind. BMC Med. Ethics 2020, 21, 17. [CrossRef] [PubMed]

(C) 2020 by the authors. Licensee MDPI, Basel, Switzerland. This article is an open access article distributed under the terms and conditions of the Creative Commons Attribution (CC BY) license (http://creativecommons.org/licenses/by/4.0/). 